\title{
TESES E DISSERTAÇÕES \\ SOBRE ENVELHECIMENTO PRODUZIDAS \\ NA UNIVERSIDADE FEDERAL DO RIO \\ GRANDE DO SUL E INCLUIDAS NO SISTEMA \\ DE BIBLIOTECAS NO ANO DE 2014
}

\section{Sergio Antonio Carlos ${ }^{1}$}

O presente levantamento de teses e dissertações sobre envelhecimento produzidas na UFRGS e incluídas no sistema de Bibliotecas no ano de 2014, como os anteriores, foi realizado a partir do Catálogo Online (Sabi) e do Lume (repositório digital). Foram utilizados os seguintes descritores: Antienvelhecimento, Educação: pessoa idosa, Envelhecimento, Geriatria, Gerontologia, Idoso, Memória (quando relacionada com o envelhecimento ou com pessoa idosa), Odontologia Geriátrica, Pessoa Idosa, Qualidade de vida: idoso, Saúde do idoso, Terceira Idade, Velhice. Foram localizadas 12 (doze) teses e dissertações defendidas nos PPGs de Administração, Antropologia Social, Ciências Biológicas: Fisiologia, Desenvolvimento Rural, Educação, Enfermagem, Epidemiologia, Informática da Educação, e Letras. Não apresentamos o resumo nem a indicação de acesso da dissertação de mestrado em Epidemiologia "Associação entre duração do sono e mortalidade em idosos: revisão sistemática com metanálise" por esta informação não estar disponibilizada no Sistema de Bibliotecas. As

1 Editor da revista Estudos Interdisciplinares sobre o Envelhecimento, professor titular no Departamento de Serviço Social do Instituto de Psicologia da UFRGS. 
demais teses e dissertações são apresentadas com seu resumo e indicação para a localização do texto completo no Repositório Digital da UFRGS: LUME.

BILLING, Johanna Dagort. Impacto do bilinguismo nas redes de atenção, no acesso lexical e na memória de trabalho em adultos e idosos. 2014. 165 f. Tese (Doutorado em Letras)-Programa de Pós-Graduação em Letras, Instituto de Letras da Universidade Federal do Rio Grande do Sul, Porto Alegre, 2014. Ori.: FINGER, Ingrid. Disponível em: <http://hdl.handle.net/10183/90172>.

resumo

Evidências sugerem que o bilinguismo possa atuar como reserva cognitiva e atenuar possíveis efeitos negativos do envelhecimento. Entretanto, há ainda muita divergência na literatura no que se refere aos mecanismos responsáveis por essa possível vantagem, sendo que a falta de um controle maior de variáveis de confusão pode explicar essa divergência. É nesse contexto que se insere a pesquisa relatada nesta tese, que teve como objetivo investigar a extensão do impacto do bilinguismo nas redes de atenção, no acesso lexical e na memória de trabalho em uma amostra composta por 136 indivíduos de duas faixas etárias (jovens de 40 a 55 anos e idosos de 60 a 71 anos), sendo 68 bilíngues (hunsrückisch-português) e 68 monolíngues (português), comparáveis em termos socioeconômicos, educacionais e funcionais. Bilíngues e monolíngues tiveram um desempenho similar em todas as tarefas; entretanto, a magnitude do efeito de envelhecimento em termos de tempo de reação geral na tarefa ANT, que avaliou as redes de atenção, na tarefa de fluência fonológica, que avaliou o acesso lexical, e na tarefa N-back, utilizada para avaliar a capacidade de memória de trabalho, foi menor para os bilíngues. Em outras palavras, nossos resultados sugerem que o bilinguismo atuou como uma espécie de reserva cognitiva. Esses resultados são discutidos com base no contexto cultural e de produção bilíngue desses participantes, chamando a atenção para a importância de se levar em consideração esses aspectos na avaliação neuropsicológica.

COSTA, Francine Melo da. Estratégias desenvolvidas pelos idosos para morarem sozinhos. 2013. 80 f. Dissertação (Mestrado em Enfermagem)-Programa de Pós-Graduação em Enfermagem, Escola de Enfermagem da Universidade 
Federal do Rio Grande do Sul, Porto Alegre, 2013. Ori.: MORAIS, Eliane Pinheiro de. Disponível em: <http://hdl.handle.net/10183/97654>.

\begin{abstract}
resumo
O estudo teve como objetivo geral analisar as estratégias desenvolvidas pelos idosos para morarem sozinhos. O número de pessoas idosas que vivem sozinhas cresce constantemente, contudo este pode ser um fator de risco para morbidade, mortalidade e pior qualidade de vida. É necessário conhecer quais são as estratégias desenvolvidas pelos idosos para que possam morar sozinhos frente às dificuldades que surgem com o processo de envelhecimento. Trata-se de uma pesquisa qualitativa do tipo exploratória. Participaram 14 idosos residentes na comunidade pertencente à área de abrangência de uma unidade básica de saúde do município de Porto Alegre. As informações foram coletadas por meio de entrevista com perguntas abertas e fechadas e analisadas por meio de análise de conteúdo temática, com o apoio do software Nvivo 8.0. Os idosos tinham idade entre 60 e 91 anos, sendo 11 mulheres e moravam sozinhos em média há 19 anos ( $\mathrm{DP} \pm 14,2$ ). $\mathrm{O}$ principal motivo para morarem sozinhos era em razão da morte das pessoas com as quais conviviam. Para a análise das estratégias foram constituídas três categorias de acordo com os comportamentos identificados. Estratégia 1: comportamentos em busca de apoio social, ou seja, buscar o apoio da família, dos amigos e vizinhos; ser fonte de apoio para a família; morar próximo daqueles que fornecem o apoio e manter proximidade/bom relacionamento nas relações afetivas. Estratégia 2: comportamentos em busca de manter-se ativo, incluindo praticar atividades de lazer e participar de atividades da comunidade. Estratégia 3: comportamentos em busca de religiosidade, como rezar/orar para ter saúde e rezar/orar para evitar a solidão. Os achados indicaram que as estratégias desenvolvidas pelos idosos mostraram-se adequadas, pois, apesar do estilo de vida independente, eles apresentavam limitações inerentes ao processo de envelhecimento, necessitando de apoio para realizar as atividades da vida diária e não se sentir sozinhos. Essas necessidades eram supridas exclusivamente pela rede de apoio informal. Mais alternativas de apoio formal deveriam ser desenvolvidas, qualificando a prática assistencial e permitindo o planejamento de ações de saúde voltadas a esses indivíduos, em uma perspectiva de avaliação individual e de apoio social.
\end{abstract}

ELSNER, Viviane Rostirolla. Modulação do exercício físico sobre mecanismos epigenéticos em encéfalos de ratos em diferentes fases do desenvolvimento. 2014.92 f.: il. 
Tese (Doutorado em Ciências Biológicas: Fisiologia)-Programa de Pós-Graduação em Ciências Biológicas: Fisiologia, Instituto de Ciências Básicas da Saúde da Universidade Federal do Rio Grande do Sul, Porto Alegre, 2014. Ori.: SIQUEIRA, Ionara Rodrigues. Disponível em: <http://hdl.handle.net/10183/90098>.

\section{resumo}

A epigenética é considerada como a interface entre os componentes genéticos, o ambiente externo e o estilo de vida. Estudos recentes sugerem uma relação entre o processo de envelhecimento cerebral e o desequilíbrio de mecanismos epigenéticos, contudo, estes dados ainda não são conclusivos. Ainda, tem sido demonstrado que o exercício físico parece alterar marcadores epigenéticos em hipocampo de ratos adultos jovens. Sabe-se que o grau de neuroplasticidade varia com a idade e que as estruturas encefálicas podem responder diferentemente à exposição ao exercício. Assim, este trabalho teve como objetivo central investigar o impacto do exercício físico sobre parâmetros epigenéticos em hipocampo e estriado de ratos Wistar em diferentes fases do desenvolvimento. Na primeira etapa, avaliou-se os efeitos do processo de envelhecimento e do exercício físico sobre parâmetros de metilação, conteúdo das enzimas DNA metiltransferase 1 (DNMT1) e DNA metiltransferase 3b (DNMT3b) e níveis de metilação da histona H3-K9 em hipocampos de ratos Wistar adultos jovens (3 meses) e envelhecidos (20 meses). Os animais foram submetidos a diferentes protocolos de exercício físico: sessão única, que constituiu em corrida em esteira durante 20 minutos, ou treinamento crônico, caracterizado pela corrida em esteira por 20 minutos durante duas semanas. Ainda, no intuito de verificar os efeitos agudos e tardios do exercício, os animais foram decapitados 1 ou 18 horas após a sessão única ou o último treino do protocolo crônico. Observou-se um perfil de hipometilação global nos animais envelhecidos, uma vez que este grupo apresentou uma redução no conteúdo hipocampal da enzima DNMT1 e nos níveis de metilação da histona H3-K9. A sessão única de exercício reduziu agudamente o conteúdo hipocampal das enzimas DNMT1 e DNMT3b no grupo adulto jovem, um indicativo de aumento da atividade transcricional e expressão gênica. No entanto, não afetou estes marcadores no grupo envelhecido. Além disto, a sessão única de exercício induziu uma redução nos níveis de metilação da histona H3-K9 no grupo adulto jovem, enquanto que, no grupo envelhecido induziu um aumento neste parâmetro em ambos os tempos testados. Ainda, o protocolo crônico reduziu de forma persistente este parâmetro no grupo adulto jovem, mas não alterou em ratos envelhecidos. Na segunda etapa, analisou-se o efeito destes mesmos protocolos de exercício sobre a atividade global da enzima 
Histona Desacetilase (HDAC) em estriado de ratos Wistar em diferentes fases do desenvolvimento, adolescentes ( 25 dias), adultos jovens ( 3 meses) e envelhecidos (20 meses). A sessão única de exercício induziu efeitos persistentes na atividade da HDAC nos adolescentes, visto que o grupo exercitado apresentou uma diminuição neste parâmetro em ambos os tempos testados, sugerindo um aumento nos níveis de acetilação de histonas e ativação da maquinaria transcricional. No entanto, o exercício não alterou a atividade desta enzima nos demais grupos, ratos adultos jovens e envelhecidos. Estes resultados sugerem que o exercício físico moderado de corrida em esteira é capaz de induzir mudanças epigenéticas em encéfalo de ratos, o que pode alterar a atividade transcricional, e assim, modular a expressão de genes específicos envolvidos com a função cerebral. Além disso, demonstramos que a modulação epigenética em resposta ao exercício ocorre de forma protocolo e idade-dependentes.

ESTEVES, Priscila Silva. Uso da internet pelo consumidor da terceira idade: influências do risco percebido e impacto na intenção de compra online. 2014. 271 f.: il. Tese (Doutorado em Administração)-Programa de Pós-Graduação em Administração, Escola de Administração da Universidade Federal do Rio Grande do Sul, Porto Alegre, 2014. Ori.: SLONGO, Luiz Antonio. Disponível em: <http://hdl.handle.net/10183/98328>.

\section{resumo}

Atualmente, observa-se que o ambiente virtual está cada vez mais povoado por pessoas com 60 anos ou mais e com os mais diversos interesses, todavia, verifica-se que há pouco conhecimento sobre como os consumidores idosos formam julgamentos e tomam decisões a respeito de produtos e serviços oferecidos na Internet, chegando a existir, inclusive, um pré-conceito de que estes indivíduos não são usuários da Internet e, portanto, não merecem que se façam investimentos para adequar produtos e serviços a eles. Sabe-se que diferentes fatores podem influenciar o comportamento do consumidor em sua tomada de decisão, principalmente quando se abordam produtos e serviços tecnológicos. Frente a esse contexto, é fundamental que se compreendam melhor os elementos que estão presentes nesse comportamento de consumo e as suas implicações futuras. Por essa razão, a presente pesquisa foi elaborada, pretendendo-se identificar os principais construtos que influenciam o comportamento do consumidor da terceira idade na Internet e analisar o seu impacto sobre a intenção de compra online. Objetivando responder a tal questionamento, 
projetou-se este estudo, para o qual foi elaborado um modelo teórico (testado empiricamente) contendo diversas variáveis e moderadores. Após 5 pré-testes e 8 entrevistas em profundidade, um questionário foi aplicado em 430 respondentes com 60 anos ou mais que tivessem utilizado a Internet pelo menos uma vez nos últimos 3 meses. O processamento de dados incluiu uma análise fatorial exploratória e uma confirmatória e a Modelagem de Equações Estruturais. Ao final deste estudo, obteve-se aceitação plena de cinco hipóteses, parcial de três e rejeição de duas, além de um bom ajuste do modelo proposto (a partir dos índices pré-definidos). Confirmou-se a hipótese de que o risco percebido pelos consumidores da terceira idade ao utilizar a Internet é um moderador no modelo estrutural proposto, uma vez que se comprovou diferença estatística significante entre as respostas dadas por um grupo mais avesso ao risco (Grupo 1) e outro menos avesso ao risco (Grupo 2) no que concerne às características demográficas e comportamentais (relacionadas ao uso da Internet). Já a escala de Tipo de Uso não se mostrou adequada para analisar a utilização da Internet pelo público da terceira idade. Constatou-se, da mesma forma, que a idade cognitiva influencia, de maneira inversa, no tempo de uso da Internet e que a satisfação com o uso da mesma tem impacto positivo no boca-a-boca positivo realizado, na intenção de (re)compra online e, também, no tempo de uso da rede. Acredita-se que os resultados obtidos a partir do teste do modelo apresentado possam fornecer importantes implicações acadêmicas e gerenciais, as quais possibilitarão uma maior compreensão sobre o uso da Internet por indivíduos da terceira idade, seus impactos futuros e a existência de moderadores importantes nesta relação.

FONTOURA, Daniele dos Santos. Envelhecimento e mercado de trabalho no setor hoteleiro brasileiro e português: uma perspectiva de gênero. 2014. 323 f.: il. Tese (Doutorado em Administração)-Programa de Pós-Graduação em Administração, Escola de Administração da Universidade Federal do Rio Grande do Sul, Porto Alegre, 2014. Ori.: PICCININI, Valmiria Carolina. Co-Ori.: FERREIRA, Sara Cristina Falcão Gonçalves Casaca. Disponível em: <http://hdl.handle.net/10183/107269>.

\section{resumo}

A tese desenvolvida interliga três constructos por si só complexos: envelhecimento, gênero e mercado de trabalho. O processo de envelhecimento é vivido na singularidade por cada indivíduo, sendo que vários fatores intervém. Como não é um fenômeno livre de gênero (Casaca \& Boud, 2012), para compreender a relação entre envelhecimento e mercado de trabalho é igualmente fundamental 
integrar a perspectiva de gênero considerando as especificidades de mulheres e homens ao envelhecer que, em alguns casos, acentuam-se com o envelhecimento (Perista \& Perista). Partindo do pressuposto que o mercado de trabalho é dinâmico, relacional e historicamente construído (Rocha-de-Oliveira, 2009) o acesso às oportunidades de trabalho é pautado, muitas vezes, por mecanismos que escapam a racionalidade e remetem às crenças, aos valores e às normas destes mercados (Guimarães, 2009). Desta forma, nesta tese buscou-se defender que as características adscritas de idade - no caso, do processo de envelhecimento - e do gênero delimitam e constrangem as experiências laborais dos/as trabalhadores/as no mercado de trabalho em Hotelaria no Brasil e em Portugal. Para o efeito, realizou-se um estudo qualitativo e comparativo entre Brasil e Portugal. Foram analisados dados secundários oriundos de estatísticas oficiais dos dois países a fim de apresentar como o envelhecimento populacional está refletindo no envelhecimento da força de trabalho e caracterizar a situação do emprego para homens e mulheres mais velhos/as. Os dados primários foram coletados na cidade de Porto Alegre/RS (Brasil) e Lisboa e arredores (Portugal) via entrevistas semiestruturadas com informantes privilegiados/as, trabalhadores/as e estudantes em Hotelaria. Ao todo, foram realizadas 20 entrevistas no Brasil e 23 em Portugal. Os resultados apontam para uma forte segmentação por idade e por gênero no mercado de trabalho em hotelaria. Diversos elementos tanto mercantis quanto não mercantis interferem na delimitação dos espaços de circulação destes/as trabalhadores/as fazendo com que o setor seja associado ao trabalho dos jovens e das mulheres. Tanto os/as informantes privilegiados/as quanto os/as trabalhadores/as e estudantes sinalizam em suas entrevistas que o idadismo e o sexismo seguem presentes nas relações de trabalho em hotelaria, fazendo com que as demandas emocionais e corpóreas recaiam mais sobre as mulheres e estejam fortemente associadas às representações do que é ser um/a trabalhador/a mais velho/a em hotelaria. Logo, nas etapas finais da vida laboral o envelhecimento e o gênero funcionam como elementos articuladores das trajetórias no mercado de trabalho em Hotelaria, delimitando e constrangendo o acesso às oportunidades de trabalho em um cenário no qual os/as mais velhos/as tem sido os/as mais prejudicados/as.

GÓMEZ, Julia Gallego. Velhos lutadores sociais do Uruguai: histórias de resiliência. 2014. 124 f. Dissertação (Mestrado em Educação)-Programa de Pós-Graduação em Educação, Faculdade de Educação da Universidade Federal do Rio Grande do Sul, Porto Alegre, 2014. Ori.: DOLL, Johannes. Disponível em: $<$ http://hdl. handle.net/10183/106444>. 
resumo

Este estudo tem como objetivo analisar, através de uma metodologia qualitativa de entrevistas narrativas, as histórias de vida e os processos de resiliência presentes nelas, de cinco pessoas que foram lutadores sociais e presos políticos durante a Ditadura Civil-Militar no Uruguai. Em meados do século passado, depois das duas Guerras Mundiais e com a economia capitalista em crise, a conjuntura do mundo se encaminhou para fatos que reclamaram posições individuais e coletivas, pois o mundo estava dividido em dois grandes blocos: o socialista e o capitalista. Na América Latina vivenciou-se uma história em comum entre muitos países, com a militância por mudanças no sistema e a repressão e defesa da economia capitalista através de ditaduras militares. Com o Plano Condor, dirigido pelos Estados Unidos e implementado pelos militares de cada país, a repressão e a procura por pessoas subversivas foi generalizada, contudo, cada país teve características próprias. No Uruguai, durante a ditadura, muitas pessoas contrárias ao regime militar sofreram fortes perseguições, com exílio, prisão, tortura e morte. Aqueles que sobreviveram, tiveram depois da abertura do sistema a dura tarefa de lidar com a violência sofrida durante o regime militar. Com o retorno à democracia (1985), iniciou-se um processo demorado em vistas à recuperação dos direitos e da justiça, processo que ainda hoje está em andamento. Esta pesquisa visa conhecer, compreender e analisar este processo, vivido por estas pessoas, a partir do conceito de "resiliência". Conceito que representa a capacidade humana de sobrepor a situações de adversidade, saindo muitas vezes ate fortalecido delas. Para isso, foram realizadas entrevistas narrativas com cinco perseguidos pelo regime militar, ex-presos políticos da ditadura. Todos os entrevistados passaram por adversidades extremas. Este trabalho pretende conhecer suas histórias e compreender, através da escuta sensível, os processos de resiliência que foram ativados para a superação dessas adversidades. Descobriremos nas narrações as experiências a que se viram enfrentados, como esses fatos influenciaram na sua vida e os mecanismos que desenvolveram para seguir adiante. Através da análise das entrevistas destes lutadores sociais, apreciamos como foram importantes a motivação à luta social, a experiência de repressão, do cárcere e da tortura e a reinserção na sociedade. Pudemos observar fatores protetores em comum abordados pelos entrevistados, como foram a ideologia, a consciência política, a presença do grupo familiar apoiador e o coletivo, representado pelos companheiros de luta. Outros fatores particulares também foram descritos nas narrativas do trabalho. Nas considerações finais, salienta-se os principais elementos ativados a fim de que sirvam de base para possíveis processos de superação em pessoas que passaram por situações de extrema violência. 
MACHADO, Leticia Rocha. Construção de uma arquitetura pedagógica para cyberseniors: desvelando o potencial inclusivo da educação a distância. 2013. 190 f. Tese (Doutorado em Informática da Educação)-Programa de Pós-Graduação em Informática na Educação, Centro de Estudos Interdisciplinares em Novas Tecnologias da Educação da Universidade Federal do Rio Grande do Sul, Porto Alegre, 2013. Ori.: BEHAR, Patrícia Alejandra. Co-Ori.: DOLL, Johannes. Disponível em: <http://hdl.handle.net/10183/70608>.

\section{resumo}

A presente tese versa sobre a Educação a Distância e o desenvolvimento de estratégias pedagógicas, técnicas e metodológicas no intuito de abranger as necessidades biopsicossociais e incluir os idosos em cursos virtuais. Deste modo, o objetivo da presente pesquisa foi construir uma arquitetura pedagógica para a Educação a Distância voltada para cyberseniors. Esta necessidade surgiu da perspectiva de uma vida longa para uma grande parte da população, representando novos desafios, onde a educação a distância pode se tornar uma forma de inclusão social por suas inúmeras possibilidades. Desta forma as arquiteturas pedagógicas, como estruturas organizacionais do planejamento, podem auxiliar na discussão e reflexão sobre o tema. Para atender ao objetivo proposto, o estudo foi realizado em uma abordagem quali-quantitativa, composta por sete etapas de desenvolvimento. No decorrer das etapas foram oferecidos cursos de extensão para pessoas com 60 anos ou mais. Após a construção dos dois primeiros mapeamentos da arquitetura pedagógica, foram oferecidas seis oficinas virtuais (Espanhol. Fisioterapia, Cores, Fotografia, Trilhas Sonoras e História e Memória) no intuito de mapear indicadores para a construção da arquitetura pedagógica final. A coleta de dados foi realizada a partir de observações participantes, entrevistas, questionários e produções tecnológicas dos participantes mais velhos em ambientes virtuais de aprendizagem. Estes indicadores possibilitaram a construção da arquitetura pedagógica final onde se percebe a necessidade de aspectos gerontoeducacionais, como a resiliência e a reminiscência com os idosos. Com o estudo foi possível perceber que os idosos possuem potencial para aprender através da EAD, o que irá implicar mudanças culturais através de novas aprendizagens.

MADEIRA, Rosemary Modernel. Escola e cuidado: histórias de mulheres idosas. 2014. 203 f. Tese (Doutorado em Educação)-Programa de Pós-Graduação em Educação, Faculdade de Educação da Universidade Federal do Rio Grande 
do Sul, Porto Alegre, 2014. Ori.: DORNELES, Malvina do Amaral. Disponível em: <http://hdl.handle.net/10183/94734>.

\section{resumo}

A pesquisa realizou-se no Brasil e em Portugal, a partir de Histórias de Vida de mulheres acima de setenta anos. No Brasil, com exceção de duas depoentes, as participantes são frequentadoras de Educação de Jovens e Adultos e estão em processo de alfabetização. Em Portugal, as entrevistas realizaram-se com frequentadoras da Universidade da Terceira Idade, possuidoras de uma vivência escolar de, no mínimo, doze anos. A tese contempla aspectos filosóficos, tal como o Cuidado ontológico heideggeriano, aspectos sociológicos, tal como o ser-com maffesoliano, aspectos antropológicos, tal como a antropologia filosófica kuschiana, aspectos do processo da hominização desde uma perspectiva biológica. A análise das Histórias de Vida privilegia os fatos que, normalmente, são considerados corriqueiros como a convivência, os sonhos, as perdas, os ganhos e mostram a constituição do humano e da Instituição Escola, enquanto lugar onde o estar-com e o cuidado fundamenta a resiliência em idosos.

SILVA, Andressa Alves da. Associação entre duração do sono e mortalidade em idosos: revisão sistemática com metanálise. 2013. 127 f. Dissertação (Mestrado em Epidemiologia)-Programa de Pós-Graduação em Epidemiologia, Faculdade de Medicina da Universidade Federal do Rio Grande do Sul, Porto Alegre, 2013 Ori.: FUCHS, Sandra Cristina Pereira Costa.

(Resumo e texto na íntegra não disponíveis on-line)

SIQUEIRA, Monalisa Dias de. "Vivendo bem até mais que 100": envelhecimento, saúde e políticas públicas para idosos no Brasil. 2014. 214 f.: il. Tese (Doutorado em Antropologia Social)-Programa de Pós-Graduação em Antropologia Social, Instituto de Filosofia e Ciências Humanas da Universidade Federal do Rio Grande do Sul, Porto Alegre, 2014. Ori.: VICTORA, Ceres Gomes. Disponível em: <http://hdl.handle.net/10183/102255>.

\section{resumo}

Esta tese versa sobre envelhecimento, saúde e políticas públicas para idosos no Brasil, no contexto de transição demográfica brasileira, caracterizado por 
um significativo aumento da longevidade e suas evidentes implicações sociais, políticas e econômicas. Nesse processo emergem as questões que norteiam o trabalho que dizem respeito à construção do "idoso" como sujeito político e de direitos; à emergência da política do Envelhecimento Ativo; à participação das pessoas idosas em grupos que visam promoção de saúde e em espaços coletivos constituídos para reivindicar direitos sociais; e à responsabilização e cuidado aos idosos dependentes. Para abordar esta problemática, realizei uma pesquisa etnográfica entre os anos de 2010 e 2013 que buscou encontrar conexões relevantes entre diferentes agentes situados em esferas distintas, tais como: idosos participantes de um grupo em um Posto de Saúde em Porto Alegre; Conferências de Direito da Pessoa Idosa; documentos das políticas públicas voltadas à população idosa e Procedimentos Administrativos a favor de idosos instaurados no Ministério Público do Estado do Rio Grande do Sul. As narrativas dos idosos, a observação participante e a análise documental me levaram a compreender como um envelhecimento subjetivado pelas políticas públicas e os agenciamentos cotidianos dos idosos na relação com tais políticas e seus mediadores tem impactado tanto os diferentes modos de envelhecer, como as formas de atuação política. Estes elementos, quando colocados em diálogo nessa tese, evidenciaram tensões entre a visibilidade e a invisibilidade do grupo suscitadas pelas políticas de saúde para os idosos no Brasil.

TONEZER, Cristiane. Velhices rurais na perspectiva do desenvolvimento social ampliado: estudo de casos múltiplos na metade sul do Rio Grande do Sul. 2014. 180 f.: il. Tese (Doutorado em Desenvolvimento Rural)-Programa de Pós-Graduação em Desenvolvimento Rural, Faculdade de Ciências Econômicas da Universidade Federal do Rio Grande do Sul, Porto Alegre, 2014. Ori.: LOPES, Marta Júlia Marques. (Série PGDR: Tese n. 78) Disponível em: <http:// hdl.handle.net/10183/109269>.

\section{resumo}

Este estudo é dedicado à compreensão de experiências de envelhecimento rural nos municípios de Camaquã e Canguçu na perspectiva do desenvolvimento social ampliado. Insere-se em um Programa Interdisciplinar de Pesquisa que busca integrar enfoques multidisciplinares e interdisciplinares na análise do desenvolvimento rural em municípios da Metade Sul do Estado do Rio Grande do Sul. Analisa as convergências e/ou divergências das evidências sociais, os reflexos na vida prática das populações rurais envelhecidas, considerando a 
transição demográfica no país e a noção de desenvolvimento social ampliado. Trata-se de um estudo de casos múltiplos (multicaso), do tipo qualitativo. A geração dos dados deu-se por meio de pesquisa documental das políticas públicas setoriais que se embasam no envelhecimento populacional e nas dimensões locais dessas políticas e em entrevistas e grupos focais, com 31 gestores e prestadores de serviços dos municípios estudados. Desenvolveram-se dois grupos focais, um em Camaquã e outro em Canguçu, participando em cada grupo oito idosos rurais. A análise considerou o conteúdo temático e as formas como apareceram nas comunicações as dimensões sociopolíticas da problemática estudada. Os resultados mostraram o envelhecimento crescente tanto em Camaquã quanto em Canguçu, com destaque para o rural. Constatou-se que as velhices rurais expressam as incongruências da implementação das políticas públicas referendadas em tratados e políticas nacionais e internacionais. Observaram-se características e limitações próprias do rural, expressas e diferenciadas entre os espaços da agricultura familiar, dos assentamentos rurais e das fazendas, encontrando-se os dois últimos em situação desfavorável se comparados ao primeiro. No plano da vida prática, para suprir a carência da oferta de ações e serviços públicos aos idosos no rural, o Sindicato dos Trabalhadores Rurais de Camaquã e de Canguçu assumem papel importante na vida dessa população. É possível afirmar que, considerando o desenvolvimento social ampliado, tanto em Camaquã quanto em Canguçu os idosos rurais encontram-se "des" (não) envolvidos nas ações e serviços, quer nos limites do rural dos municípios como em termos de inclusão na sociedade mais ampla.

ZENI, Rafael Rosa. Os valores pessoais dos idosos e as fases da lealdade. 2013. 102 f.: il. Dissertação (Mestrado em Administração)-Programa de Pós-Graduação em Administração, Escola de Administração da Universidade Federal do Rio Grande do Sul, Porto Alegre, 2013. Ori.: NIQUE, Walter Meucci. Disponível em: <http://hdl.handle.net/10183/77741>.

\section{resumo}

O envelhecimento da população é um fenômeno mundial. Os baixos níveis de fecundidade e o aumento da expectativa de vida provocam mudanças na estrutura etária dos países, impactando em aspectos sociais, legais e econômicos. Neste contexto, o consumidor idoso torna-se cada vez mais atrativo, caracterizado por sua disponibilidade de renda, autonomia e comportamento de consumo distinto dos estereótipos outrora a ele atribuídos. Adotando essa 
perspectiva, a presente pesquisa explora a relação entre Valores Pessoais e as Fases da Lealdade dos Consumidores idosos, utilizando como "pano de fundo" o comportamento de compra de automóveis. A base teórica deste estudo se apoia na Teoria Motivacional de Schwartz (1992), que apresenta Valores Pessoais como "princípios guia" dos comportamentos humanos, e no modelo de Fases da Lealdade proposto por Oliver $(1997 ; 1999)$, que classifica o grau de lealdade dos consumidores sob aspecto comportamental e atitudinal. Foram entrevistados 207 consumidores com idade igual ou superior a 60 anos e 2 gestores de concessionárias. Os primeiros participaram da etapa quantitativa e responderam a uma pesquisa do tipo Survey, o que permitiu a realização de testes estatísticos bivariados e multivariados. Os últimos analisaram os achados obtidos na etapa quantitativa por meio de entrevistas em profundidade. Os resultados indicaram que a estrutura de Valores Pessoais dos idosos aproxima-se da dimensão de Autotranscedência, na qual se destacam o Universalismo e a Benevolência, o que lhes atribui comportamentos orientados ao bem estar dos outros. A fase da Lealdade encontrada em maior nível no perfil dos consumidores idosos foi a Cognitiva-Afetiva, o que revela a importância da experiência cumulativa oriunda de repetidas situações de compra e uso. O estudo do relacionamento entre os construtos evidenciou relacionamento positivo e de fraca intensidade, o que contribui para a caracterização dos Valores Pessoais como um dos preditores das Fases da Lealdade. 